\title{
Recognition and management of depression in early psychosis
}

\author{
Zainab Bashir, ${ }^{1}$ Sian Lowri Griffiths, ${ }^{2}$ (1) Rachel Upthegrove ${ }^{2,3}$ (1)
}

BJPsych Bulletin (2022) 46, 83-89, doi:10.1192/bjb.2021.15

\author{
${ }^{1}$ Assertive Outreach Team and \\ Psychiatric Intensive Care Unit, \\ Birmingham and Solihull Mental Health \\ Foundation Trust, UK; ${ }^{2}$ Institute for \\ Mental Health, University of \\ Birmingham, UK; ${ }^{3}$ Birmingham Early \\ Intervention Service, Birmingham \\ Women's and Children's NHS \\ Foundation Trust, UK \\ Correspondence to Dr Sian Lowri \\ Griffiths (s.l.griffiths@bham.ac.uk) \\ First received 16 Jul 2020, final revision \\ 19 Jan 2021, accepted 27 Jan 2021 \\ (c) The Author(s), 2021. Published by \\ Cambridge University Press on behalf of \\ the Royal College of Psychiatrists. This is \\ an Open Access article, distributed \\ under the terms of the Creative \\ Commons Attribution-NonCommercial- \\ ShareAlike licence (http:// \\ creativecommons.org/licenses/by-nc- \\ $\mathrm{sa} / 4.0 /$ ), which permits non- \\ commercial re-use, distribution, and \\ reproduction in any medium, provided \\ the same Creative Commons licence is \\ included and the original work is \\ properly cited. The written permission of \\ Cambridge University Press must be \\ obtained for commercial re-use.
}

Aims and method Depression in first-episode psychosis (FEP) is highly prevalent and associated with poor outcomes; it has become increasingly recognised and adopted in national and international guidelines for psychosis. Using a 26-item questionnaire, this study aimed to explore if this shift has led to greater recognition among UK psychiatrists, and more effective management of depression in FEP.

Results Of the 297 respondents, 54.4\% observed depression occurring in chronic psychosis, with the least number of respondents (17.7\%) identifying depression occurring frequently during FEP. Although there was reasonable agreement in the use of antidepressants as a first-line treatment for depression (70\% prescribing antidepressants), there was uncertainty around assessing depression and delineating from psychosis symptoms, and particularly negative symptoms.

Clinical implications Evidence-based treatments for comorbid depression in psychosis will lead to clearer national guidelines, allowing for optimal management of depression in early psychosis, potentially leading to improved outcomes for these individuals.

Keywords Comorbidity; psychotic disorders; antidepressants; depressive disorders; early intervention.
Depression is prevalent in first-episode psychosis (FEP), with rates of up to $70 \%$ at illness onset. ${ }^{1}$ It is associated with a higher risk of relapse, ${ }^{2}$ poorer functional outcomes ${ }^{3,4}$ and suicide. ${ }^{5}$ Although the National Institute for Health and Care Excellence (NICE) recommends monitoring for depression within psychosis, specific guidance on the treatment of comorbid depression has been limited, until recently. ${ }^{6,7}$ The lack of large-scale controlled trials investigating the effectiveness of adjunctive antidepressants ${ }^{8}$ has perhaps resulted in considerable variation in prescribing practices. ${ }^{6,9}$ A study of 80000 international psychiatrists showed little consensus on the best management strategy for treating depression in schizophrenia; a third of clinicians reported that they rarely or never prescribe antidepressants in combination with antipsychotics. ${ }^{9,10}$ Since this publication in $2001,{ }^{9}$ depression as a common occurrence in psychosis has become more widely recognised. ${ }^{11,12}$ Monitoring for depression in psychosis is featured more commonly in national and international guidelines, $^{7}$ and the recent British Association for Psychopharmacology updated consensus statement is the first UK guide to include specific pharmacological treatment recommendations. ${ }^{13}$
We aim to understand whether there has been an improvement in clinician awareness of depression in psychosis; this may have an impact on effective management, particularly in the early stages of psychosis, where treatment is likely to be more effective. ${ }^{14}$ Using a survey which was distributed to UK psychiatrists, this study aimed to explore the level of recognition and management of depression through the course of FEP.

\section{Method}

\section{Participants}

Participants were members of the Royal College of Psychiatrists, which is a professional organisation of psychiatrists based in the UK. The sample therefore comprised psychiatrists of various ages and career stage, from those in training to consultant level. Although there are around 8700 psychiatrists registered at the Royal College of Psychiatry, the survey was targeted at, and only distributed to, the general adult faculty. Participants were given the opportunity to enter into a prize draw to win $£ 200$ worth of Amazon vouchers. 


\begin{abstract}
Measures
Management of Depression in Psychosis questionnaire

The Management of Depression in Psychosis questionnaire is a shortened version of Siris et al's original questionnaire. ${ }^{9}$ It was felt to be the most suitable as it was designed to evaluate clinician awareness and management approach. It also allows for comparison of trends of psychiatric practices in assessing and managing depression in psychosis over time. The questionnaire has been adapted to focus on the identification of depression and prescribing in the early course of psychosis. For the purpose of this study, recognition of depression is defined as assessing for the three cardinal symptoms of depression, namely low mood, anhedonia and anergia. The questionnaire was built into Survey Monkey for ease, practicality and anonymous online administration. The questionnaire was completed anonymously and comprised 23 questions relating to the following: demographic characteristics of the respondents (e.g. gender, years since graduation, specialty/subspecialty and region of practice); recognition of symptoms relevant to the diagnosis of depression; depression time course in psychosis; factors and symptoms that prompt the prescription of antidepressants; evaluation measures; and treatment selection and practice (e.g. medication dose and duration).
\end{abstract}

\section{Procedure}

The questionnaires were completed over a period of 2 months after being granted ethical approval and agreed sponsorship by University of Birmingham (REC Reference: ERN_18-1658). Participants were provided with information about the study, informed of the voluntary nature of their participation, and reminded that responses were anonymous with the option to opt in for the prize draw. Written informed consent was obtained from all participants.

\section{Data analysis}

Data were downloaded from Survey Monkey (see http://www. surveymonkey.co.uk/r/Depression_in_psychosis_survey) and inspected using a Microsoft Excel (365 for Windows) worksheet. Descriptive statistics were explored using SPSS version 24 for Windows.

\section{Results}

In total, there were 297 respondents; although on average, it was observed that a third of the participants who completed the survey also skipped at least one question in the questionnaire. A total of $52 \%$ were male, and on average, the sample had 21 years (s.d. 11.5) of practice since graduating from medical school. Responses by geographical regions were as follows: London (13.4\%), South-East (12.4\%), West Midlands (11.9\%), South-West (11.9\%) and Scotland $(11.9 \%)$. We had the least responses from Wales (2.6\%), Northern Ireland (2.6) and East Midlands (3.6\%), and $26.8 \%$ of participants did not give a response. The majority of the respondents were clinicians that practiced within community settings $(67.7 \%)$.

\section{Observed prevalence and time course of depression in psychosis}

A total of $41.2 \%$ of participants had a case-load of which patients with psychosis comprised $>50 \%$; $46.6 \%$ had between $5-50 \%$ and $1.3 \%$ had $<5 \%$. The majority of respondents reported observing depression occurring concurrently with chronic stable psychosis (54.4\%), and $23 \%$ reported depression occurring concurrently with acute relapse. With regards to depression emerging in the initial phase of illness, $19.1 \%$ observed depression within the prodromal phase to the acute psychotic phase; $32.4 \%$ reported depression emerging as the first acute episode of psychosis resolves, and $17.7 \%$ of respondents reported observing depression during the first episode of psychosis.

\section{Assessment and diagnosis of depression in psychosis}

Respondents were asked to select the first five most relevant symptoms they consider in diagnosing depression in psychosis: $93.2 \%$ identified low mood, $68.3 \%$ identified anhedonia, $57.1 \%$ identified suicidal thoughts, $53.2 \%$ identified poor motivation and $48.3 \%$ identified interest in life as a symptom. Please see Fig. 1 for the full breakdown of symptoms reported by respondents.

The majority of participants reported not utilising a specific interview system to inform a diagnosis of depression in psychosis (96.6\%). In terms of employing depression evaluation measures, $35.1 \%$ of respondents reported using none, 39.1\% used the Beck Depression Inventory, 28.5\% used the Hamilton Rating Scale for Depression, 17.2\% used the Brief Psychiatric Scale and 9.3\% used the Calgary Depression Scale for Schizophrenia (CDSS).

\section{Recognition and management of depression in psychosis}

Participants were asked about which clinical guidelines they used to aid the recognition and management of depression in psychosis: $61.5 \%$ of respondents used NICE guidelines, $50.0 \%$ used the Maudsley Prescribing Guidelines, 27.6\% used British Association for Psychopharmacology guidelines and $12.0 \%$ used BJPsych Advances(previously known as Advances in Psychiatric Treatment) articles; the remainder mainly used clinical experience.

\section{Treatment approaches}

\section{Antidepressant therapy}

The majority of respondents reported that antidepressant medication would be their first line of treatment for psychosis with comorbid depression (69.5\%), 32.5\% indicated cognitive-behavioural therapy, $12.3 \%$ reported a 'watch and wait approach' and $7.4 \%$ would reduce the dose of the prescribed antipsychotic medication.

In terms of factors that would prompt prescribing of an antidepressant, $84.2 \%$ reported a family history of depression, $40.4 \%$ reported poor interpersonal and social skills, $39.2 \%$ reported 'living alone' and $29.8 \%$ reported a 'recent loss or rejection'. Key symptoms prompting a prescription of an antidepressant medication included hopelessness (80.1\%), low mood (76.5\%) and suicidal ideation (75.5\%). 
Fig. 1 Breakdown of main symptoms identified by respondents to diagnose depression in psychosis.

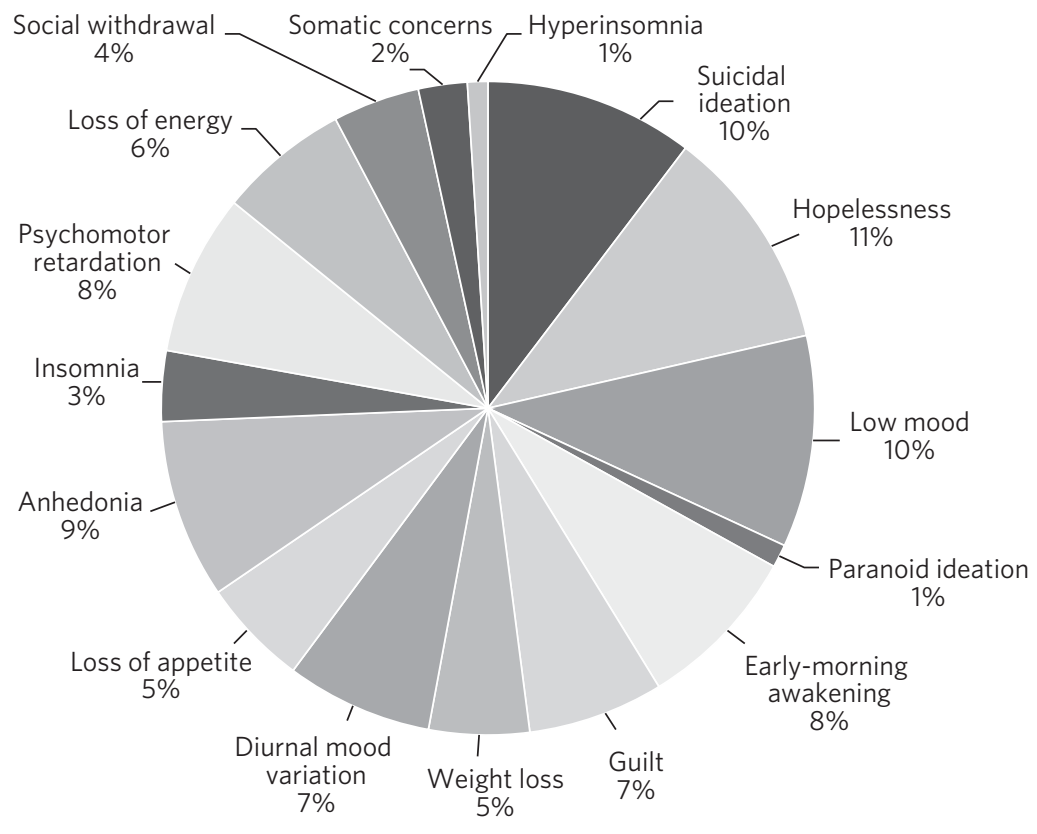

With regards to antidepressants prescribed in early psychosis with comorbid depression, selective serotonin reuptake inhibitors were generally preferred; the majority of respondents opted for sertraline (85.4\%), followed by mirtazapine (49.8\%), fluoxetine $(45.4 \%)$ and venlafaxine (33.7\%). Interestingly, $28.8 \%$ of participants opted for citalopram and $15.1 \%$ opted for escitalopram. Please see Fig. 2 for the proportions of antidepressants prescribed.

\section{Antipsychotic therapy}

Participants were asked about antipsychotics they routinely prescribe for young people with early psychosis. Atypical antipsychotic agents were the most commonly prescribed:
$66.0 \%$ of respondents opted for aripiprazole, $54.2 \%$ opted for olanzapine, $52.2 \%$ opted for risperidone and $44.3 \%$ opted for quetiapine. Clozapine was selected by $9.9 \%$ of respondents. Please see Fig. 3 for the proportion of antipsychotics prescribed.

Drug combinations and treatment duration In terms of conjunctive antidepressant and dopamine antagonist prescribing, $55.7 \%$ reported they would not frequently prescribe this combination, $35.8 \%$ reported often prescribing and $8.5 \%$ affirmed that they very often prescribe this combination.

A total of $13.5 \%$ of respondents stated that they would completely avoid mirtazapine and olanzapine in
Fig. 2 Proportions of antidepressants reported to be prescribed as first-line treatments for depression in early psychosis

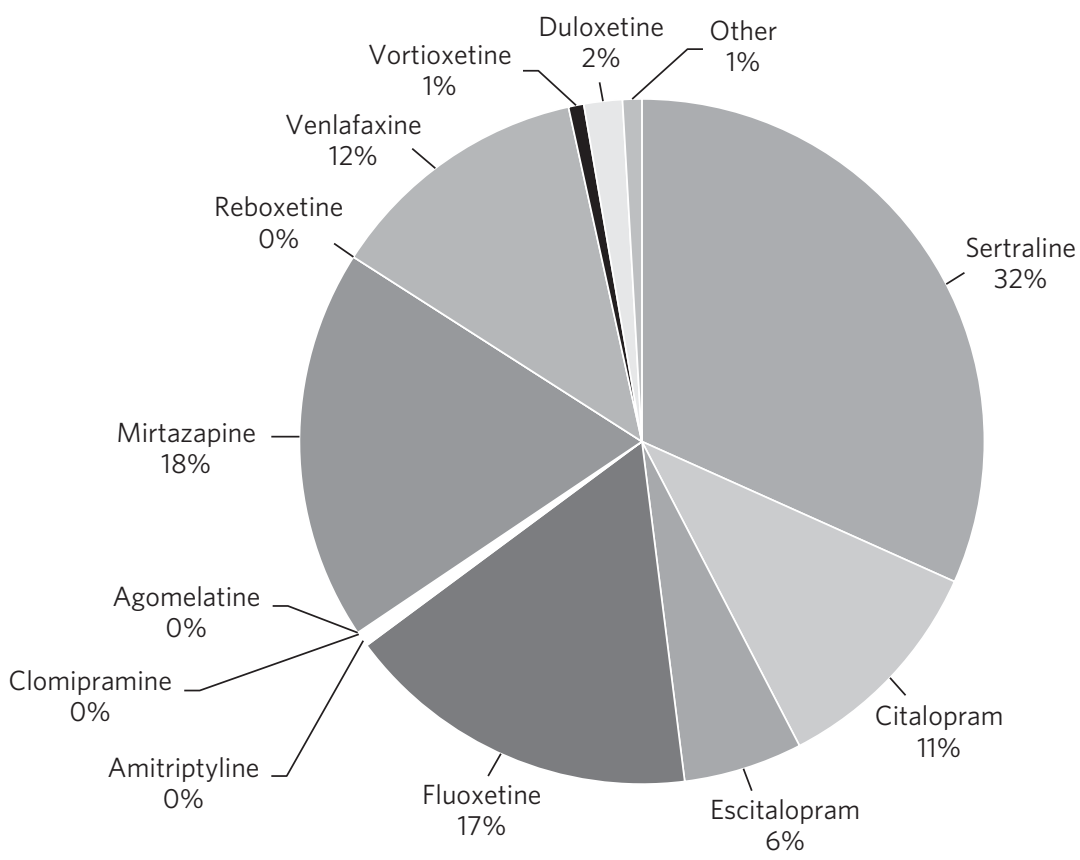




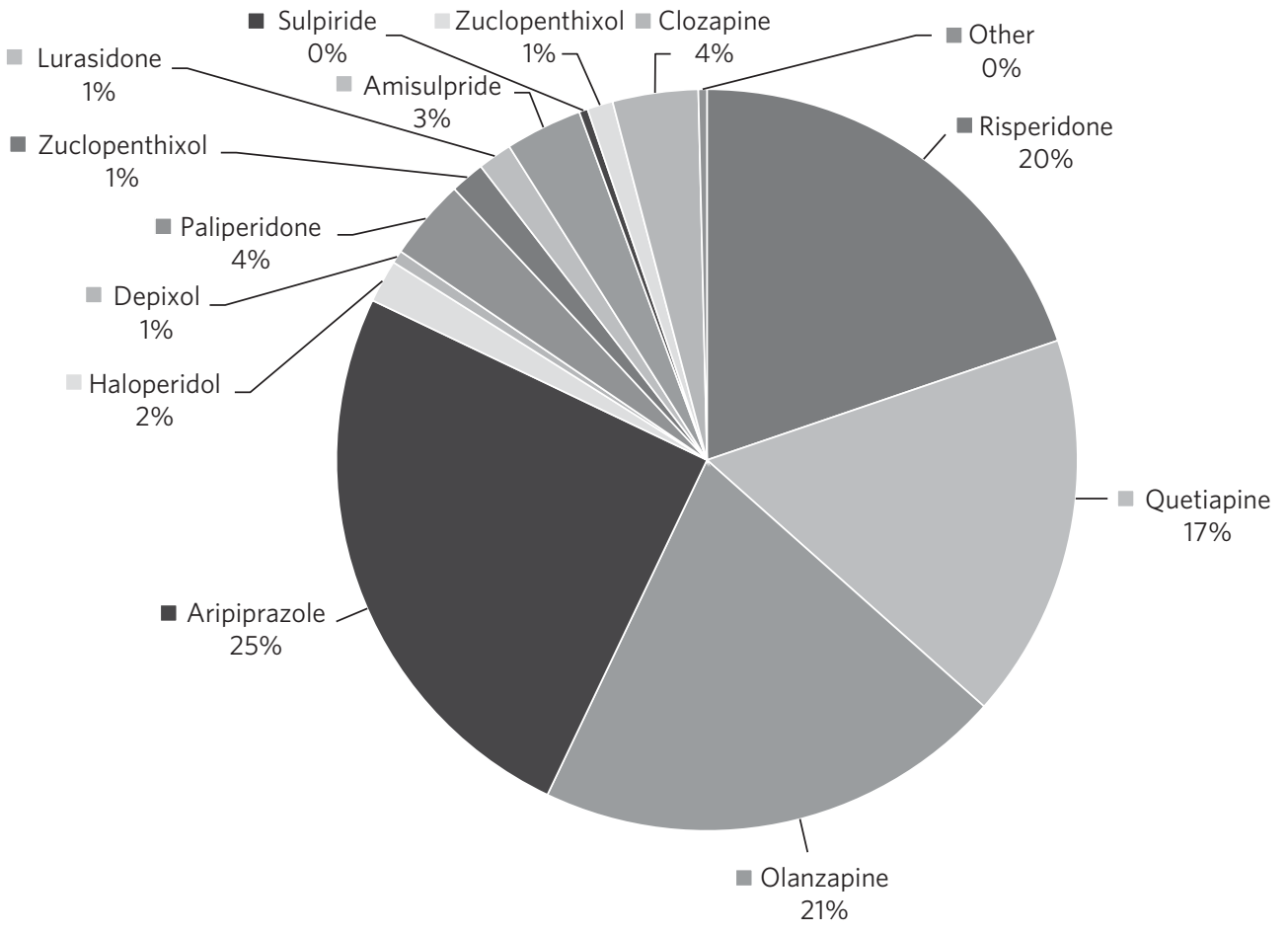

Fig. 3 Proportions of antipsychotics prescribed by respondents.

combination, with a handful citing reasons such as weight gain and oversedation; $14.4 \%$ stated they would actively avoid citalopram and antipsychotics in combination, with some citing reasons such as increased risk of corrected QT interval prolongation; and $42.3 \%$ reported that there were no combinations that they would actively avoid.

With regards to duration of therapy, $47.8 \%$ of respondents estimated expecting clinical benefits within 2-4 weeks of adding antidepressant to dopamine antagonist therapy, $43.3 \%$ thought it would likely take $4-6$ weeks and $7.5 \%$ predicted improvement in 6-12 weeks. The majority of participants $(77.5 \%)$ felt that antidepressant therapy should continue for 6-12 months once the individual showed a satisfactory response, $15.7 \%$ felt that therapy should continue for $>12$ months and $8.3 \%$ felt that therapy should continue for 3-6 months. In terms of physical health monitoring when coprescribing, $77.9 \%$ monitored heart rhythm via electrocardiogram, monitored blood chemistry (prolactin, glucose and lipid profile), $73.4 \%$ monitored bloods (prolactin, glucose and lipid profile) and $42.9 \%$ undertook a physical examination. However, 18.2\% reported that no physical health interventions were carried out.

\section{Non-pharmacological treatment approaches}

On average, most respondents prescribed non-pharmacological therapies for depression in FEP, with $82.1 \%$ opting for psychoeducation and cognitive-behavioural therapy, $67.2 \%$ opting for psychosocial interventions and $42.3 \%$ opting for family interventions. A further $10.5 \%$ of participants reported prescribing electroconvulsive therapy, and a handful opted for lifestyle interventions and supportive psychotherapy.

\section{Reflections from respondents}

Overall, about a third of the participants highlighted difficulty in delineating negative symptoms of psychosis from depression during a period of psychosis. Others described the complex interactions of positive and cognitive symptoms that are hard to disentangle, as well as the possibility of an affective illness occurring as the primary driver for psychosis. Many respondents expressed keenness in offering psychology or psychotherapy, but cited problems with availability at the time of need.

\section{Discussion}

This study aimed to gauge the level of recognition and management approaches used by UK psychiatrists to manage and treat depression in psychosis. With depression in psychosis now being adopted in national and international clinical guidelines, ${ }^{7}$ we wanted to explore whether any change in recognition has led to more effective management of depression in those with psychosis, particularly in the early stages of illness.

Overall, the majority of respondents (69.5\%) indicated the use of antidepressant medication as a first line of treatment for young people with psychosis and comorbid depression. There was reasonable agreement among clinicians on the contextual factors and key symptoms that would prompt a prescription of antidepressant medication. For example, the majority of respondents reported low mood and anhedonia as the major symptoms for diagnosing depression $(93 \%$ and $68 \%$, respectively), with $45 \%$ also identifying anergia as a core symptom. Over $80 \%$ of participants reported that they would routinely prescribe a selective serotonin reuptake inhibitor (sertraline in particular). This indicates a reasonable 
agreement between clinicians on the best strategy for managing comorbid depression with psychosis. These findings demonstrate a possible shift in the management strategy since Siris et al's ${ }^{9}$ earlier publication, where a third of clinicians reported that they would rarely prescribe antidepressants in adjunct to antipsychotic medication.

Although previous studies have reported $70 \%$ prevalence rates of depression at illness onset, ${ }^{1}$ our study showed fewer respondents (19\%) identified depression as occurring frequently in FEP; instead, 54\% reported observing depression occurring with stable psychosis. This might suggest that depression in the early phases of psychosis is still underrecognised; this is concerning, given that young people in particular are at heightened risk of suicide within the first 12 months following the initial episode of psychosis. ${ }^{15,16}$ However, it must also be acknowledged that the findings from our survey are reliant on the memory of clinicians, with a potential for recall bias, and so the accuracy of these findings may be challenged.

Despite a consensus on treatment strategies for depression, what became apparent from the survey was the uncertainty around assessing depression and delineating from psychosis symptoms, and particularly negative symptoms. Interestingly, a large proportion do not employ structured interview schedules to inform their assessment, which could aid this delineation. In particular, the CDSS was only used by $9 \%$ of respondents. The CDSS is a short and easily used instrument, designed specifically for the assessment of depression in psychosis, as it distinguishes between negative and positive symptoms. ${ }^{17}$ Better promotion of these evaluation measures may be warranted.

There were also reports of challenges faced by clinicians in determining if the symptoms were part of an affective component of the psychotic episode, potentially highlighting the need for a better understanding of the diagnostic uncertainty and course of depression in early psychosis. ${ }^{18}$

Over the past two decades, there appears to have been a shift in prescribing of antipsychotic medications - particularly from the first generation (typical) to second generation (atypical) agents. ${ }^{19}$ This is also reflected in our survey, where the majority were prescribing atypical agents such as aripiprazole, olanzapine, risperidone and quetiapine, compared with $4.9 \%$ and $3.9 \%$ of respondents prescribing haloperidol and zuclopenthixol. Thus, there appears to be a particular preference toward the antipsychotics believed to have the least side-effects, but not with recognition that some antipsychotics may have more antidepressant properties, ${ }^{20}$ or possibly promote depression, such as haloperidol. ${ }^{13}$

In regards to coprescribing in the present study, most respondents reported that there were no combinations of antidepressants and antipsychotics that they would actively avoid; however, some did express actively avoiding citalopram and antipsychotic in combination, with some citing risk of prolongation of the corrected QT interval. A similar percentage reported they would actively avoid a combination of mirtazapine and olanzapine because of increased risk of weight gain and sedation. In line with this, the majority of respondents $(>70 \%)$ stated that they provided routine physical health monitoring when coprescribing. These findings indicate that clinicians are perhaps more cognisant of the potential physical health problems caused by antipsychotic medications, and may suggest proactiveness in mitigating such risks. Although this finding is encouraging, recent data shows that only $32.3 \%$ of individuals with severe mental illness in England receive a full physical health check. ${ }^{21,22}$ Given the lowered life expectancy of individuals with schizophrenia, the current NICE recommendations advocate for annual physical health checks for all individuals with severe mental health problems. ${ }^{23}$ Improving physical health monitoring should remain a top priority. ${ }^{22}$

\section{Implications for clinical practice}

Our results may indicate further training and embedding of routine assessment tools into clinical practice is be needed to further increase the recognition and management of depression, which, if achieved, could improve outcomes. Indeed, this finding is in keeping with the wider literature on the difficulty of promoting the use of instruments, such as the CDSS, into routine practice. ${ }^{24} \mathrm{~A}$ suggestion may be to embed these instruments into electronic patient records, and include monitoring of comorbidities as part of quality improvement programmes, and national audits such as the National Clinical Audit of Psychosis. ${ }^{25}$

\section{Study strengths and limitations}

This study was the first to explore clinician recognition and management of depression in young people with FEP. Although the survey was completed by 297 clinicians, responses were underrepresented in certain parts of the country (particularly Wales, Northern Ireland and East Midlands), and overall response rate was low. On average, a third of the participants who completed the survey also returned incomplete questionnaires, affecting the overall representativeness of the information provided.

This study relied on the clinician reflecting on their previous practice, awareness and general approach, and they were provided with multiple options for each question. As such, there is a potential for recall bias. Furthermore, some questions were focused on depression within psychosis more generally, meaning that responses were less specific to depression in FEP. It is also very likely that clinicians within the Early Intervention Service and those with more interest in this field may have been more involved in the survey. An Amazon voucher was also offered as an incentive for participation, again, further introducing a respondent bias.

Another limitation was in disseminating the survey. Because of regulations governing the Royal College of Psychiatry, emails were only distributed to members registered under the General Adult Psychiatry faculty. The questionnaire was not disseminated to other psychiatric disciplines that may have been relevant, such as Child and Adolescent Mental Health Service, and Forensic or Learning Disability subspecialties. Finally, the survey was UK-based, with a low response rate. Further research is required to understand whether these practices are uniform in a larger sample of participants, and across different countries, particularly in the USA and Europe.

In conclusion, although there is now more consensus on recognising depression in early psychosis strategies, there continues to be variations in the approach toward its 
assessment and management (e.g. in the use of specific interview schedules or evaluation measures to assess depression in those with psychosis). Although our findings are tentative, given the low response rate, the survey indicates that adjunctive treatment is being administered by most clinicians; however, some expressed difficulties in differentiating between depression occurring in relation to psychosis and negative symptoms of psychosis, and there was little consensus on treatment duration and time of expectation of response. Embedding of structured assessment tools into routine practice, in addition to devising clearer national guidelines based on large definitive trials, would be instrumental in improving future practice in early psychosis, potentially leading to improved outcomes.

\section{About the authors}

Zainab Bashir (MBBS, MSc, MRCPsych) is an ST5 Psychiatry Registrar at the Psychiatric Intensive Care Unit, Birmingham and Solihull Mental Health Foundation Trust, UK. Sian Lowri Griffiths (PhD) is a Research Fellow at thelnstitute for Mental Health, University of Birmingham, UK. Rachel Upthegrove (MBBS, FRCPsych, PhD) is a Professor at the Institute for Mental Health, University of Birmingham, UK; and a Consultant Psychiatrist at the Birmingham Early Intervention Service, Birmingham Women's and Children's NHS Foundation Trust, UK.

\section{Data availability}

The corresponding and senior authors had full access to study data and had final responsibility for the decision to submit for publication. The data that support the findings of this study are available on request from the corresponding author, S.L.G. The data are not publicly available due to privacy or ethical restrictions.

\section{Acknowledgements}

We thank the Royal College of Psychiatrists for supporting our research by distributing our study information to its members. We also thank the clinicians who took time to participate in this study.

\section{Author contributions}

R.U. was the chief investigator and funds recipient. S.L.G. and Z.B. designed the study protocol and survey. The data were analysed by Z.B. and S.L.G. Z.B. and S.L.G. drafted the manuscript, with further input from R.U. All authors provided comments on the manuscripts and approved the final version.

\section{Declaration of interest}

R.U. reports grants from Medical Research Council, the National Institute for Health Research's Health Technology Assessment and the European Commission's Seventh Framework Programme, and personal fees from Sunovion, outside the submitted work.

An ICMJE form is in the supplementary material, available online at https://doi.org/10.1192/bjb.2021.15.

\section{References}

1 Birchwood M, labal Z, Chadwick $\mathrm{P}$, Trower $\mathrm{P}$. Cognitive approach to depression and suicidal thinking in psychosis: I. Ontogeny of postpsychotic depression. Br J Psychiatry 2000; 177(6): 516-21.

2 Heiden W, Häfner $H$. The epidemiology of onset and course of schizophrenia. Eur Arch Psychiatry Clin Neurosci 2000; 250(6): 292-303.

3 Sands JR, Harrow M, Sands JR, Harrow M. Depression during the longitudinal course of schizophrenia. Schizophr Bull 1999; 25: 157-71.
4 Delahanty J, Ram R, Postrado L, Balis T, Green-Paden L, Dixon L. Differences in rates of depression in schizophrenia by race. Schizophr Bull 2001; 27: 29-38.

5 Crumlish N, Whitty P, Kamali M, Clarke M, Browne S, McTigue O, et al. Early insight predicts depression and attempted suicide after 4 years in first-episode schizophrenia and schizophreniform disorder. Acta Psychiatr Scand 2005; 112(6): 449-55.

6 Gregory A, Mallikarjun P, Upthegrove R. Treatment of depression in schizophrenia: systematic review and meta-analysis. $\mathrm{Br} J$ Psychiatry 2017; 211(4): 198-204.

7 Dondé C, Vignaud P, Poulet E, Brunelin J, Haesebaert F. Management of depression in patients with schizophrenia spectrum disorders: a critical review of international guidelines. Acta Psychiatr Scand 2018; 138(4) 289-99.

8 Helfer B, Samara M, Huhn M, Klupp E, Leucht C, Zhu Y, et al. Efficacy and Safety of Antidepressants Added to Antipsychotics for Schizophrenia: A Systematic Review and Meta-Analysis. Am J Psychiatry 2016; 173(9): 876-86.

9 Siris SG, Addington D, Azorin J-M, Falloon IRH, Gerlach J, Hirsch SR Depression in schizophrenia: recognition and management in the USA. Schizophr Res 2001; 47(2): 185-97.

10 Addington D, Azorin J M, Falloon I RH, Gerlach J, Hirsch S, Siris S. Clinical issues related to depression in schizophrenia: an international survey of psychiatrists. Acta Psychiatr Scand 2002; 105(3): 189-95.

11 Flint AJ, Meyers BS, Rothschild AJ, Whyte EM, Alexopoulos GS, Rudorfer MV, et al. Effect of continuing olanzapine vs placebo on relapse among patients with psychotic depression in remission: the STOP-PD II randomized clinical trial. JAMA 2019; 322(7): 622-31.

12 Rothschild AJ. Challenges in the treatment of major depressive disorder with psychotic features. Schizophr Bull 2013; 39(4): 787-96.

13 Barnes TR, Drake R, Paton C, Cooper SJ, Deakin B, Ferrier IN, et al. Evidence-based guidelines for the pharmacological treatment of schizophrenia: updated recommendations from the British Association for Psychopharmacology. J Psychopharmacol 2020; 34(1): 3-78.

14 Birchwood M, Todd $P$, Jackson C. Early intervention in psychosis: the critical period hypothesis. Br J Psychiatry 1998; 172(S33): 53-9.

15 Dutta R, Murray RM, Hotopf M, Allardyce J, Jones PB, Boydell J. Reassessing the long-term risk of suicide after a first episode of psychosis. Arch Gen Psychiatry 2010; 67(12): 1230-7.

16 McGinty J, Sayeed Haque M, Upthegrove R. Depression during first episode psychosis and subsequent suicide risk: a systematic review and meta-analysis of longitudinal studies. Schizophr Res 2018; 195: 58-66.

17 Addington D, Addington J, Schissel B. A depression rating scale for schizophrenics. Schizophr Res 1990; 3(4): 247-51.

18 Upthegrove R, Marwaha S, Birchwood M. Depression and schizophrenia: cause, consequence, or trans-diagnostic issue? Schizophr Bull 2016; 43(2): 240-4

19 Leucht S, Corves C, Arbter D, Engel RR, Li C, Davis JM. Second-generation versus first-generation antipsychotic drugs for schizophrenia: a meta-analysis. Lancet 2009; 373(9657): 31-41.

20 Goodwin GM, Haddad PM, Ferrier IN, Aronson JK, Barnes T, Cipriani A et al. Evidence-based guidelines for treating bipolar disorder: revised third edition recommendations from the British Association for Psychopharmacology. J Psychopharmacol 2016; 30(6): 495-553.

21 Butler J, de Cassan S, Turner P, Lennox B, Hayward G, Glogowska M. Attitudes to physical healthcare in severe mental illness; a patient and mental health clinician qualitative interview study. BMC Fam Pract 2020; 21(1): 243 .

22 NHS England. Physical Health Checks for People with Severe Mental Illness. NHS England, 2019 (https://www.england.nhs.uk/statistics/statisticalwork-areas/serious-mental-illness-smi/).

23 Kendall T, Hollis C, Stafford M, Taylor C. Recognition and management of psychosis and schizophrenia in children and young people: summary of NICE guidance. BMJ 2013; 346: f150. 

and management of depression in primary care. Qual Saf Health Care 2003; 12: 149-55.

25 Royal College of Psychiatrists. National Clinical Audit of Psychosis National Report for the Early Intervention in Psychosis Spotlight Audit

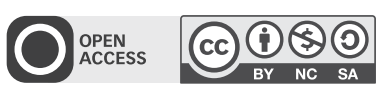

\title{
ORIGINAL PAPER
}

\section{Risk, demand, capacity and outcomes in adult specialist eating disorder services in South-East of England before and since COVID-19}

\author{
Agnes Ayton, ${ }^{1}$ (1) David Viljoen, ${ }^{1}$ Sharon Ryan, ${ }^{1}$ Ali Ibrahim, ${ }^{2}$ Duncan Ford ${ }^{1}$
}

BJPsych Bulletin (2022) 46, 89-95, doi:10.1192/bjb.2021.73

${ }^{1}$ Oxford Health NHS Foundation Trust, UK; ${ }^{2}$ Berkshire Eating Disorder Service, Berkshire NHS Foundation Trust, UK

Correspondence to Agnes Ayton (suchagnes@gmail.com)

First received 18 Dec 2020, final revision 7 Jun 2021, accepted 1 Jul 2021

(c) The Author(s), 2021. Published by Cambridge University Press on behalf of the Royal College of Psychiatrists. This is an Open Access article, distributed under the terms of the Creative Commons Attribution-NonCommercialNoDerivatives licence (http:// creativecommons.org/licenses/by-ncnd/4.0/), which permits non-commercial re-use, distribution, and reproduction in any medium, provided the original work is unaltered and is properly cited. The written permission of Cambridge University Press must be obtained for commercial re-use or in order to create a derivative work.
Aims and method This is a longitudinal cohort study describing the demand, capacity and outcomes of adult specialist eating disorder in-patient services covering a population of 3.5 million in a South-East England provider collaborative before and since the COVID-19 pandemic, between July 2018 and March 2021.

Results There were 351 referrals for admission; 97\% were female, 95\% had a diagnosis of anorexia nervosa and 19\% had a body mass index (BMI) $<13$. Referrals have increased by $21 \%$ since the start of pandemic, coinciding with reduced capacity. Waiting times have increased from 33 to 46 days. There were significant differences in outcomes between providers. A novel, integrated enhanced cognitive behaviour theapy treatment model showed a $25 \%$ reduction in length of stay and improved $\mathrm{BMI}$ on discharge ( $50 \%$ v. $16 \% \mathrm{BMI}>19)$, compared with traditional eclectic in-patient treatment.

Clinical implications Integrated enhanced cognitive behaviour theapy reduced length of stay and improved outcomes, and can offer more effective use of healthcare resources.

Keywords Anorexia nervosa; in-patient treatment; access and waiting times; COVID-19; eating disorders.

\section{National background}

In the 2019 Health Survey for England, 16\% of adults aged $\geq 16$ years ( $19 \%$ of women and $13 \%$ of men) screened positive for a possible eating disorder. This included $4 \%$ (5\% of women and $3 \%$ of men) who reported that their feelings about food had interfered with their ability to work, meet personal responsibilities or enjoy a social life. ${ }^{1}$ This is almost a threefold increase since 2007 . $^{2}$ These findings may be surprising, but are consistent with international epidemiological data. ${ }^{3}$

In parallel, hospital admissions in England of people with eating disorders have increased from 4849 in 20072008 to 19116 in 2018-2019. ${ }^{4}$ This shows an almost fourfold increase in demand, and there has been no investment in specialist eating disorder in-patient services during this time. Approximately $70 \%$ of people needing hospital admission are adults with anorexia nervosa.

On 6 November 2020, after the inquest into five avoidable deaths, the coroner for Cambridgeshire and Peterborough, concluded that National Health Service (NHS) treatment for patients with anorexia nervosa is 'not a safe system' and risks 'future deaths'. ${ }^{5}$ These statements mirror the 2017 Parliamentary Health Service Ombudsman (PHSO) report. ${ }^{6}$ Three years ago, the PHSO made several helpful recommendations, including reviewing medical education, improving the workforce, ensuring the parity of funding of services across the age range and strengthening coordination of care. There has been limited progress since. ${ }^{7}$ 